\title{
Cholecystokinin type $B$ receptor antagonist PD-136,450 is a partial secretory agonist in the stomach and a full agonist in the pancreas of the rat
}

\author{
A Schmassmann, A Garner, B Flogerzi, M Y Hasan, M Sanner, L Varga, F Halter
}

\begin{abstract}
Gastrin (cholecystokinin type B (CCK-B)) receptor antagonists may help to elucidate the physiological role of gastrin, have therapeutic potential as acid antisecretory drugs, and may be of use as adjuvant therapy for gastrin sensitive tumours. In binding studies, the gastrin receptor antagonist $\mathrm{PD}-136,450$ had at least 1000 fold greater affinity for gastrin (CCK-B) than CCK-A receptors. In this study the biological activity of PD-136,450 was evaluated in conscious and anaesthetised rats. PD-136,450 antagonised gastrin stimulated acid secretion after subcutaneous $\left(\mathrm{IC}_{50}: 0.28\right.$ $\mu \mathrm{mol} / \mathrm{kg}$; conscious rats) and intravenous ( IC $_{50}: \quad 0.17 \mu \mathrm{mol} / \mathrm{kg}$; anaesthetised rats) administration. In basal secreting fistula animals, the compound stimulated acid output to $30(5) \%$ of the maximal response to gastrin. Stimulant activity was not caused by gastrin release. As an agonist $\mathrm{PD}-136,450$ was about 350 times less potent than gastrin-17 on a molar basis. In addition, PD-136,450 was a powerful agonist of pancreatic secretion in anaesthetised rats. The specific gastrin antagonist L-365,260 inhibited the (partial) agonist activity of PD-136,450 in the stomach and the specific CCK-A receptor antagonist L-364,718 inhibited the agonist activity of PD-136,450 in the pancreas. It is concluded that the agonist effect of PD-136,450 is mediated via interaction with the gastrin (CCK-B) receptor in the stomach and the CCK-A receptor in the pancreas.
\end{abstract}

(Gut 1994; 35: 270-274)

Gastrointestinal Unit, University Hospital, Inselspital, Bern, Switzerland A Schmassmann B Flogerzi M Sanner L Varga F Halter

Department of Pharmacology and Therapeutics, Faculty of Medicine and Health Sciences, UAE University, Al Ain, United Arab Emirates A Garner M Y Hasan

Correspondence to: Correspondence to: Professor F Halter, Gastrointestinal Unit, Hospital, 3010 Bern, Switzerland. Switzerland.

Accepted for publication 16 June 1993
Considerable progress has been made in elucidating the physiological and pathological roles of gastrin in recent years. This has been aided by the discovery of non-peptide antagonists of gastrin (cholecystokinin type B (CCK-B)) receptors, by molecular cloning of the gastrin receptor itself, and by identification of receptors for gastrin on enterochromaffin-like (ECL) cells from mastomys gastric tumours. ${ }^{1-10}$ Receptor antagonists have a potential use in peptic ulcer disease and as adjuvant therapy in gastrin receptor positive gastrointestinal tumours, since they not only antagonise acid secretion but also inhibit the trophic effect of gastrin on gastric mucosa, endocrine cell populations, and gastrin receptor positive malignant tumour cells. ${ }^{112}$ Gastric ECL cell hyperplasia and the possibility of inducing carcinoid tumours remain potential concerns during long term treatment with proton pump blockers.

CCK-A (pancreatic type) and CCK-B (gastric/ brain type) receptor antagonists are closely related in structure and pharmacological properties and most of the compounds are ligands for both CCK and gastrin receptors. ${ }^{713}$ Two CCK-B receptor antagonists have been the focus of recent attention-PD-136,450, also referred to as Cam-1189, is a dipeptoid analogue, ${ }^{1-5}$ while $\mathrm{L}-365,260$ is a benzodiazepine derivative..$^{6-8}$ These antagonists bind to CCK-B receptors in the stomach and brain where they display antisecretory and anxiolytic properties respectively. Compared with L-365,260, PD-136,450 displays a higher binding affinity for CCK-B receptors $\left(\mathrm{IC}_{50}=0.6 \mathrm{nM}\right.$ in the guinea pig gastric mucosa and $\mathrm{IC}_{50}=0.7 \mathrm{nM}$ in mouse cerebral cortex) and seems to be a more potent and longer acting antagonist of gastrin induced acid secretion in vivo. ${ }^{251213} \mathrm{PD}-136,450$ has also been reported to inhibit ECL cell hyperplasia induced by chronic achlorhydria and endogenous hypergastrinaemia during treatment with a proton pump inhibitor. ${ }^{12}$

While studying antagonism of gastrin induced acid secretion by PD-136,450, we also observed an agonist response at higher doses in both the stomach and pancreas which prompted us to study the effects of PD-136,450 on acid and pancreatic secretions in detail.

\section{Methods}

ACID SECRETION STUDIES IN CONSCIOUS GASTRIC FISTULA RATS

Female Wistar rats weighing about $200 \mathrm{~g}$ were fitted with a chronic gastric fistula as described previously. ${ }^{14}$ The cannulas were implanted at least four weeks before the onset of acid secretory studies. At the start of experiments, the rats had a body weight of 240-260 g. During the entire study period, animals were kept under normal laboratory conditions with free access to water and standard rat chow. Over the course of the experiments, which lasted four to six weeks, the rats remained well and showed an average weight gain of $40 \mathrm{~g}$.

PD-136,450 belongs to a class of recently described $\alpha$-methyl-(R)-tryptophan dipeptoid gastrin receptor antagonists. It has the chemical name $\left[R-\left(R^{\star}, R^{\star}\right)\right]-4-[[2-[[3-(1 H-I n d o l-3-y l)-$ 2methyl-1-oxo-2-[[(tricyclo[3·3 $\left.1 \cdot 1^{3,7}\right]$ dec2-oxy)carbonyl] amino] propyl]amino]-1phenylethyl] amino]-4-oxo-2-butanoate $\mathrm{N}$ methyl-D-glucamine and was kindly supplied by Professor J Hughes, Parke-Davis Neuroscience Research Unit, Cambridge, UK. Synthesis, chemical properties, receptor binding affinities, and preliminary biological activities, have been 
described recently. ${ }^{1-5}$ The specific gastrin (CCK-B) receptor antagonist L-365,260 and the specific CCK-A receptor antagonist L-364,718 were kindly provided by $\operatorname{Dr} \mathrm{R} M$ Freidinger, Merck Sharp \& Dohme Research Laboratories, West Point, Pennsylvania, USA.

Studies were performed in a total of 36 different animals with a 'wash out' period of at least two days between experiments. Animals were fasted for 20 hours before studies. To study antagonist activity, rats were pretreated with PD-136,450 (4.5 mg/kg subcutaneously) or vehicle, and 15 minutes, two, four, or eight hours later $32 \mu \mathrm{g} / \mathrm{kg}$ gastrin (SHG-17, Fluka, Buchs, Switzerland) were injected subcutaneously. Agonist activity was studied in a separate group of rats by subcutaneous injection of either PD-136,450 (0.01-18 mg/kg) or gastrin $(0.03-32$ $\mu \mathrm{g} / \mathrm{kg}$ ) at six different doses per compound. A third set of rats was used to determine whether the specific gastrin antagonist L-365,260 inhibited the (partial) agonist activity of PD-136,450 on acid secretion. Animals were pretreated with L-365,260 $(4.5 \mathrm{mg} / \mathrm{kg}$ subcutaneously) or vehicle and five minutes later, $4 \cdot 5$ $\mathrm{mg} / \mathrm{kg}$ PD-136,450 were also given subcutaneously.

During experiments, animals were restrained in Bollmann cages. The stomach was rinsed with $0.15 \mathrm{~mol} / \mathrm{l}$ saline solution $\left(38^{\circ} \mathrm{C}\right)$ and allowed to drain for 30 minutes before collecting samples of gastric juice in 30 minute intervals. The $\mathrm{pH}$ was determined with a combined glass calomel $\mathrm{pH}$ electrode, GK $2321 \mathrm{C}$, after calibration with buffers at $\mathrm{pH} 4$ and 7 . Acidity was measured by titration using a TTT2-titrator and autoburette (Radiometer, Copenhagen, Denmark). Samples were titrated with $0 \cdot 1 \mathrm{M} \mathrm{NaOH}$ to an end point of $\mathrm{pH} \mathrm{7 \cdot 4}$.

Plasma gastrin was also monitored every 30 minutes. Blood $(0.5 \mathrm{ml})$ was collected from the tail vein into plastic tubes containing $20 \mu \mathrm{l}$ heparin solution (corresponding to about $50 \mathrm{IU}$ ). The blood was centrifuged and the plasma was stored at $-70^{\circ} \mathrm{C}$. Gastrin was measured, as previously described, ${ }^{15}$ using antigastrin antiserum (a gift of Dr S R Bloom, Hammersmith Hospital, London, UK) and synthetic human gastrin I as a standard. The antibody bound and free hormones were separated by dextran coated charcoal, counted separately, and the percentage binding was calculated. The intraassay coefficient of variation was below $10 \%$. To avoid interassay variation, all samples were analysed in the same run.

\section{ACID AND PANCREATIC SECRETION STUDIES IN ANAESTHETISED RATS}

Female Wistar rats (200-260 g) were fasted overnight but given free access to water. Anaesthesia was induced and maintained by intramuscular injection of urethane $(1.5 \mathrm{~g} / \mathrm{kg})$. Body temperature was maintained at $36-37^{\circ} \mathrm{C}$ by a rectal thermistor and thermostatically controlled heated table. The trachea and an external jugular vein were cannulated.

For acid secretion studies, a flexible orogastric tube was introduced into the proximal portion of the stomach. A multi-orifice polyethylene tube was then inserted into the antrum through an incision in the duodenum and was brought to the exterior through the flank. The stomach was perfused with saline via the orogastric tube at $7 \mathrm{ml} / \mathrm{min}$ and effluent was collected over 10 minute intervals from the pyloric outlet. Samples were titrated with $0 \cdot 1 \mathrm{M} \mathrm{NaOH}$ to an end point of $\mathrm{pH} 7 \cdot 4$. Basal acid output was recorded for 30 minutes, then secretion was stimulated by intravenous injection of $1 \mu \mathrm{g} / \mathrm{kg}$ SHG-17. This control response was followed one hour later by subcutaneous injection of either vehicle or PD-136,450 $(0 \cdot 1-1 \cdot 0 \mathrm{mg} / \mathrm{kg})$. After a further 10 minutes, a second identical dose of gastrin was given and acid output was monitored for a further 60 minutes. Since there was no tachyphylaxis in the response to gastrin administered according to this protocol, the reduction of acid secretion by PD-136,450 was calculated as $\%$ of the initial response to gastrin.

For pancreatic secretion studies, pancreatic juice was collected from a fine polyethylene tube inserted into the main pancreatic duct and the volume output was measured gravimetrically. Basal pancreatic output was recorded for 30 minutes, then secretion was stimulated by intravenous injection of $0.5 \mu \mathrm{g} / \mathrm{kg}$ CCK-8. This control response was followed one hour later by a subcutaneous injection of $4.5 \mathrm{mg} / \mathrm{kg}$ PD-136,450. In a second set of experiments, we
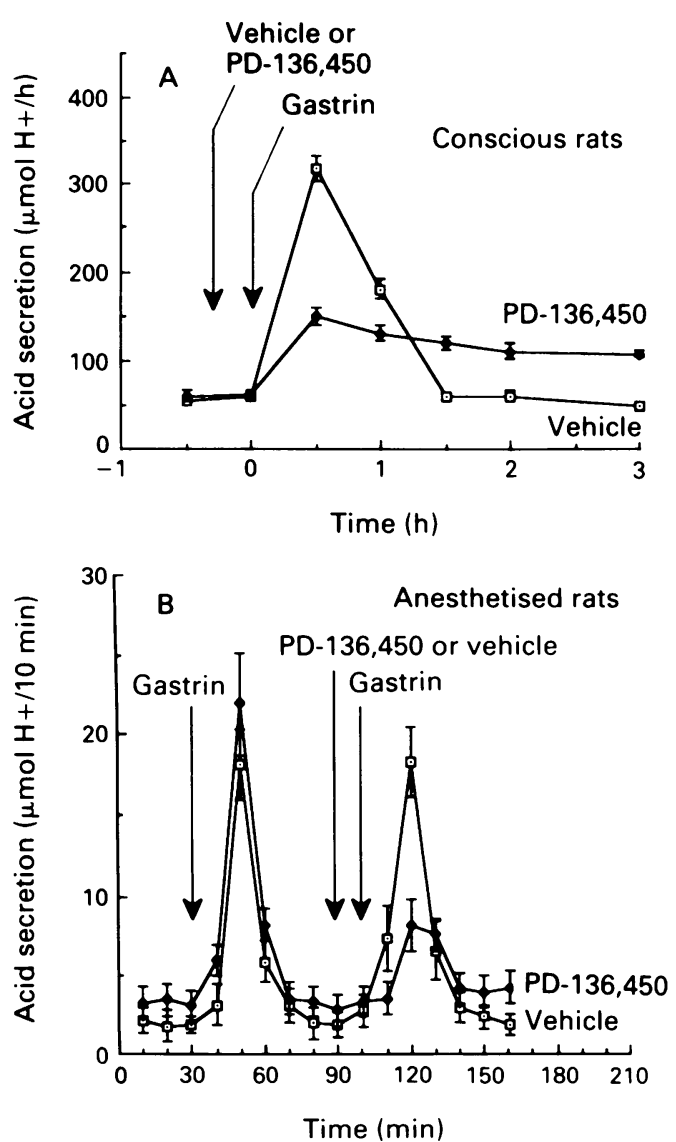

Figure 1: Antagonist effect of $P D-136,450$ on gastrin stimulated acid secretion in conscious $(A)$ and anaesthetised (B) rats. Gastrin stimulated acid secretion was reduced by 60 (5)\% (mean (SEM)) in conscious rats and by $77(3) \%$ in anaesthetised animals (PD-136,450 v vehicle; $p<0.001)$. In the experiments shown, $4.5 \mathrm{mg} / \mathrm{kg} P D-136,450$ and $32 \mu \mathrm{g} / \mathrm{kg}$ gastrin were injected subcutaneously in conscious rats while $1 \mathrm{mg} / \mathrm{kg} P \mathrm{PD}-136,450$ and $1 \mathrm{\mu g} / \mathrm{kg}$ gastrin were injected intravenously in anesthetised rats. 


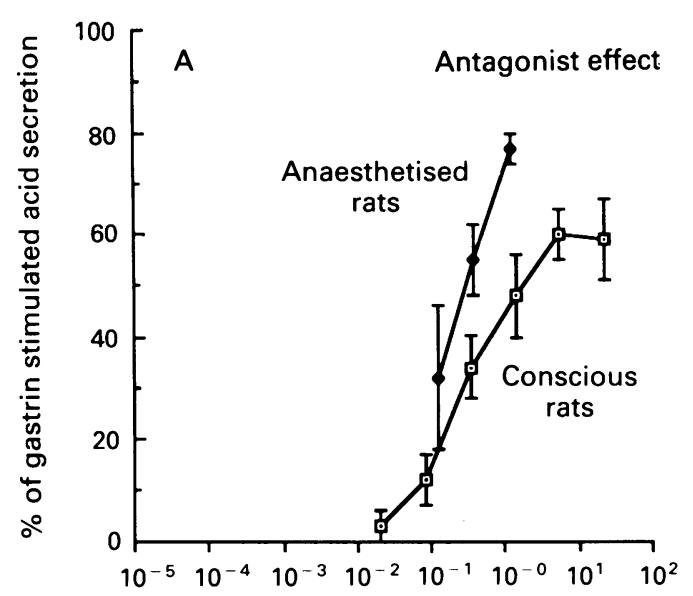

Dose of PD-136,450 ( $\mu \mathrm{mol} / \mathrm{kg})$

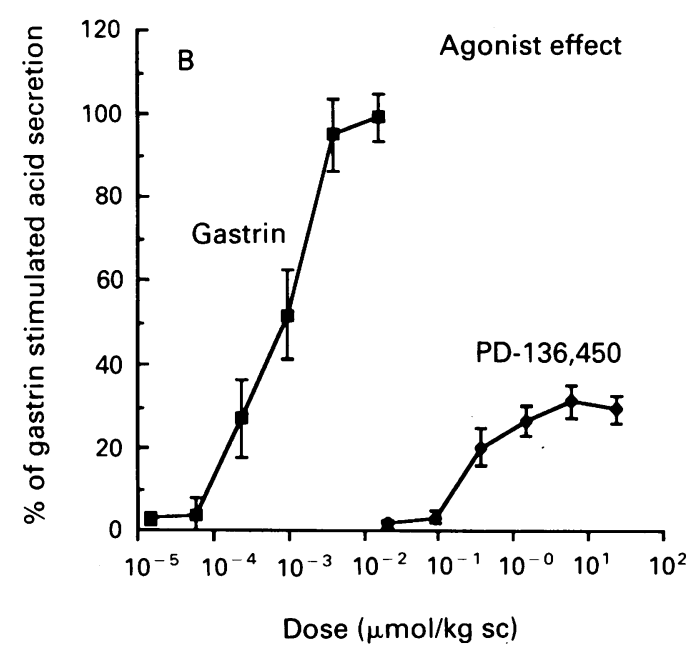

Figure 2: The upper panel (A) shows dose-responses for the antagonist effect of $P D-136,450$ on gastrin induced acid secretion in conscious and anaesthetised rats. IC $C_{50}$ values were $0.28 \mu \mathrm{mol}(0 \cdot 23 \mathrm{mg}) / \mathrm{kg}$ and $0.17 \mu \mathrm{mol}(0.14 \mathrm{mg}) / \mathrm{kg}$ in conscious and anaesthetised rats respectively. $(B)$ shows doseresponses for the agonist effect of $P D-136,450$ on acid secretion in comparison with gastrin in conscious gastric fistula rats. $P D-136,450$ increased acid output to 30 (5)\% of the maximal gastrin induced acid output $(P D-136,450 \mathrm{v}$ vehicle: $p<0.0001)$. The $E D_{50}$ of $P D-136,450$ was about $0.25 \mu \mathrm{mol}$ $(0 \cdot 2 \mathrm{mg}) / \mathrm{kg}$ and the response was maximal at $5 \cdot 6 \mathrm{\mu mol}(4 \cdot 5$ $m g) / k g$.

determined whether the specific CCK-A or CCK-B antagonists could block stimulation of pancreatic secretion by PD-136,450. Rats were pretreated with vehicle, L-365,260, or L-364,718 (both at $4.5 \mathrm{mg} / \mathrm{kg}$ subcutaneously) and five minutes later, $4.5 \mathrm{mg} / \mathrm{kg}$ PD-136,450 was injected subcutaneously.

The significance of differences was determined by unpaired $t$ test. Probability values of $\mathrm{p}<0.05$ were regarded as significant.

\section{Results}

PD-136,450 antagonised gastrin-induced acid secretion by $60(5) \%$ (mean (SEM), $\mathrm{n}=12$ ) at a dose of $4.5 \mathrm{mg} / \mathrm{kg}$ subcutaneously in conscious gastric fistula rats and by 77 (3)\% at a dose of $1 \mathrm{mg} / \mathrm{kg}$ intraveneously in anaesthetised rats by comparison with vehicle controls (Figs $1 \mathrm{~A}$ and B). Dose-response studies of the antagonist effect of PD-136,450 in conscious and anaesthetised rats produced $\mathrm{IC}_{50}$ values of $0.28 \mu \mathrm{mol}$

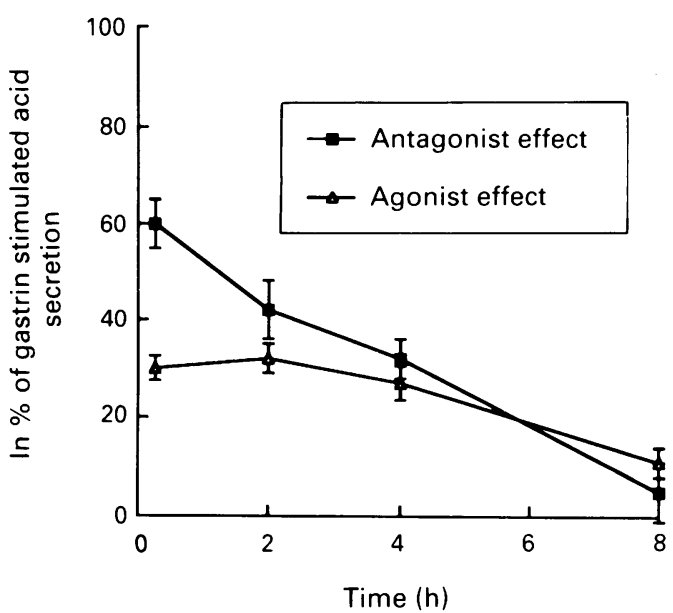

Figure 3: Duration of antagonist and agonist actions of $P D-136,450$ in the conscious rat. The effects decreased over time with a half life of four to six hours. In the antagonist study, rats were pretreated with $4.5 \mathrm{mg} / \mathrm{kg}$ subcutaneous $P D-136,450$ and challenged with $32 \mu \mathrm{g} / \mathrm{kg}$ subcutaneous gastrin $0 \cdot 25,2,4$, or 8 hours later. In the agonist study, the acid stimulatory effect of $P D-136,450$ was measured directly after subcutaneous injection of $4.5 \mathrm{mg} / \mathrm{kg}$.

$(0.23 \mathrm{mg}) / \mathrm{kg}$ and $0.17 \mu \mathrm{mol}(0.14 \mathrm{mg}) / \mathrm{kg}$ respectively (Fig 2A). PD-136,450 displayed a partial agonist action in as much as acid output in basal secreting conscious rats increased to 30 (5)\% of the maximal response to gastrin itself. Dose-response studies of the stimulation of acid secretion by PD-136,450 in conscious animals showed a maximal response at $5.6 \mu \mathrm{mol}(4.5$ $\mathrm{mg}$ )/kg (Fig 2B). Gastrin-17 displayed greater efficacy and was about 350 fold more potent on a molar basis. The agonist and antagonist activities decreased with time, although the duration of action of PD-136,450 was fairly lengthy after subcutaneous dosing (Fig 3). Pretreatment with PD-136,450 did not change the basal plasma gastrin value and did not modify the pharmacokinetics of injected gastrin (Fig 4). As shown in Figure 5, the stimulation of gastric acid secretion was completely inhibited by pretreatment with the gastrin (CCK-B) receptor antagonist L-365,260.

PD-136,450 (4.5 mg/kg subcutaneously) caused a sustained increase in pancreatic volume

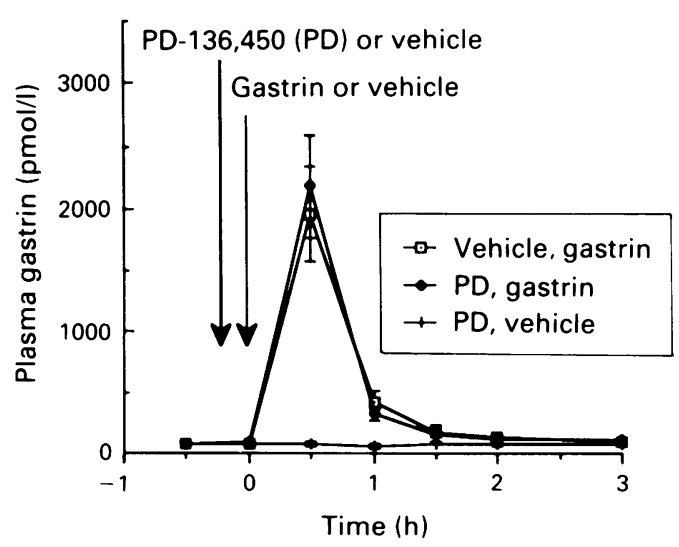

Figure 4: Effect of PD-136,450 on plasma gastrin values. Subcutaneous injection of $4 \cdot 5 \mathrm{mg} / \mathrm{kg} P D-136,450$ did not change basal gastrin concentrations (PD-136,450 first, vehicle 15 minutes later). Plasma values after subcutaneous injection of $32 \mu \mathrm{g} / \mathrm{kg}$ gastrin were unchanged after pretreatment with PD-136,450 compared with vehicle. 
Figure 5: In basal secreting animals, the gastrin receptor antagonist $L-365,260$ inhibited the (partial) agonist activity of $P D-136,450$ on acid secretion $(L-365,260 \mathrm{v}$ vehicle: $p<0.001)$. Vehicle or $4.5 \mathrm{mg} / \mathrm{kg} \mathrm{L}-365,260$ were injected subcutaneously and five minutes later, $4 \cdot 5$ $\mathrm{mg} / \mathrm{kg} P D-136,450$ were also injected subcutaneously.

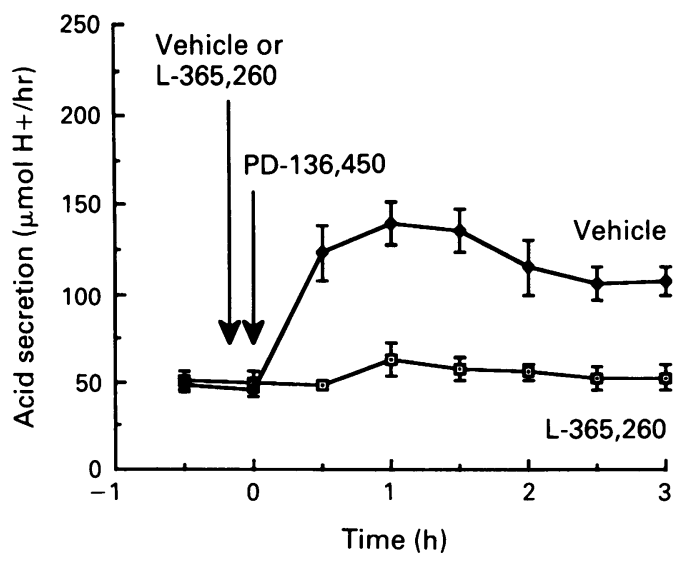

output from $5 \cdot 4(1 \cdot 3)$ to $33 \cdot 1(4 \cdot 6) \mu \mathrm{l} / 10 \mathrm{~min}$, which was slightly higher than the maximal response to an intravenous injection of CCK-8 and was maintained for at least two hours (Fig $6 \mathrm{~A})$. The increase in pancreatic flow in response to PD-136,450 was not affected by pretreatment with L-365,260 but was strongly inhibited by the CCK-A antagonist L-364,718 (Fig 6B).

\section{Discussion}

PD-136,450 belongs to a new class of orally effective gastrin antagonists that act on central and peripheral CCK-B receptors. ${ }^{1-5}$ In vitro, PD-136,450 displays a nanomolar affinity for the CCK-B receptor, with over 1000 fold selectivity

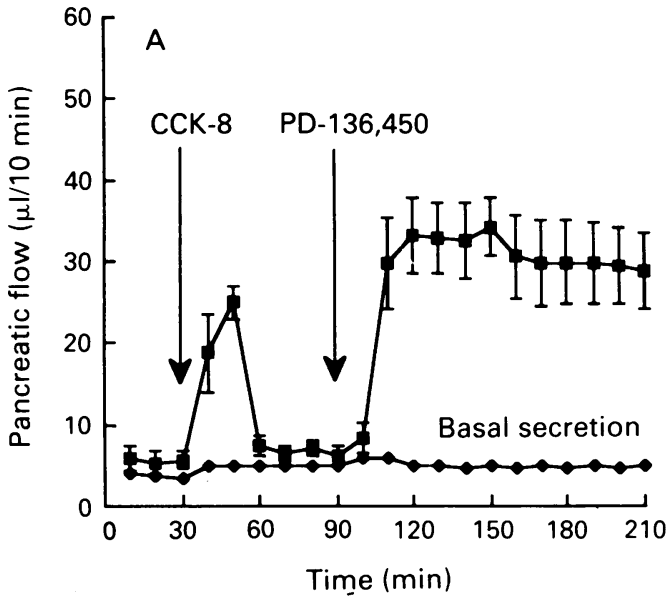
(A). $P D-136,450$ increased pancreatic secretion from mean (SEM) $5 \cdot 4(1 \cdot 3)$ to $33 \cdot 1(4 \cdot 6) \mu l / 10 \mathrm{~min}$, which exceed the output after intravenous injection of $0.5 \mathrm{mg} / \mathrm{kg}$ cholecystokinin-8 $(C C K-8)$. (B) The CCK-B receptor antagonist

$L-365,260$ did not affect the response to $P D-136,450$. In contrast, the CCK-A receptor antagonist

$L-364,718$ inhibited the agonist activity of

$P D-136,450$ on pancreatic secretion $(L-364,718$ v vehicle: $p<0.01)$. Vehicle, $4 \cdot 5 \mathrm{mg} / \mathrm{kg} \mathrm{L}-365,260$ or $4 \cdot 5$ $\mathrm{mg} / \mathrm{kg} \mathrm{L}-364,718$ were injected subcutaneously and five minutes later $4.5 \mathrm{mg} / \mathrm{kg}$ $P D-136,450$ was also injected subcutaneously. compared with CCK-A sites and a wide range of other receptors. ${ }^{2}$ PD-136,450 was developed by minor modifications from the older CCK-B receptor antagonist PD-134,308 which is currently being evaluated clinically for its anxiolytic properties. Our studies in conscious and anesthetised rats, confirm that this compound is an effective inhibitor of gastrin induced acid secretion. We found that PD-136,450 was some three times less potent than reported previously, which is probably a reflection of the differences in experimental design. Thus, previous studies ${ }^{25}$ used an intravenous infusion of pentagastrin and also administered PD-136,450 by intravenous infusion, whereas in the present experiments animals were pretreated with a bolus dose of PD-136,450 and gastrin-17 was administered 15 minutes later at submaximal bolus doses of 32 $\mu \mathrm{g} / \mathrm{kg}$ in conscious rats and $1 \mathrm{mg}$ intravenously in anaesthetised rats. PD-136,450 showed a sustained duration of action with a half-life of about four hours, which is clearly longer than that described for L-365,260 which seems to be less than one hour. ${ }^{1316}$

Although the affinity of PD-136,450 for the CCK-B receptor in vitro is in the same range as for gastrin, it behaves as a partial agonist in vivo. However, the compound shows lower efficacy and considerably lower potency than gastrin as a stimulant of acid secretion in the rat. Agonist activity amounted to about $30 \%$ of the maximal gastrin response. This seems to be a direct effect since PD-136,450 did not cause the release of endogenous gastrin and did not alter the pharmacokinetics of injected gastrin. The maximal response to $\mathrm{PD}-136,450$ occurred 30-60 minutes after administration, similar to the time at which peak behavioural effects were observed. ${ }^{3}$ Agonist and antagonist effects displayed similar sensitivity and duration of action, and there was no dose at which these two actions could be dissociated. L-365,260, which did not affect basal acid secretion, inhibited the agonist activity of PD-136,450 in the stomach. This further supports the suggestion that stimulation of acid secretion by PD-136,450 is mediated through direct interaction with gastrin receptors on parietal or ECL cells. PD-136,450 is therefore not an optimal antagonist for studying the role of gastrin. Nevertheless, in long term experiments, high doses of PD-136,450 almost completely abolished the gastrin induced increase in mucosal height, ECL cell density, and histamine concentration in the oxyntic mucosa. ${ }^{12}$

In binding studies, PD-136,450 was found to be highly selective for the CCK-B receptor with a $K_{d}$ value some 1100 times lower than for CCK-A receptors. ${ }^{2}$ In vivo, however, PD-136,450 displayed powerful stimulation of pancreatic secretion. This finding is consistent with the observation that PD-136,450 caused a noticeable increase of pancreatic weight after chronic administation at even higher doses of $18 \mathrm{mg} / \mathrm{kg}$, three times daily. ${ }^{17}$ Moreover, the present experiments show very closely that PD-136,450 exerts an effect on the pancreas via CCK-A receptors as demonstrated by the fact that the response could be antagonised by L-364,718. This action on pancreatic CCK-A receptors seems to be direct in as much as PD-136,450 is 
known to be effective in an isolated gland preparation and does not release CCK in vivo. ${ }^{17}$

In conclusion, $P D-136,450$ seems to be capable of exerting effects through both CCK-A and CCK-B recepters in vivo. It antagonises gastrin induced acid secretion, but exerts a partial agonist effect in the stomach. In the pancreas, PD-136,450 behaves as a powerful stimulant of fluid secretion via a CCK-A receptor mechanism. Studies of the binding, distribution, and metabolism of PD-136,450 in the rat in vitro and in vivo are necessary to clarify apparent discrepancies between the in vitro binding data and pharmacodynamic behaviour of the compound in vivo. Although PD-136,450 was designed for optimal activity at CCK-B receptors, further structural modification seems necessary in order to achieve selectivity of action in this series of compounds in vivo.

Parts of this study have been presented in abstract form at the Conference on Gastrin, 9-12 February 1992, Dana Point Resort, USA and the American Gastroenterological Association, 9-15 May 1992, San Francisco, USA.

1 Hughes J, Boden P, Costall B, Domeney A, Kelly E, Horwell DC, et al. Development of a class of selective cholecystokinin type B receptor antagonists having potent anxiolytic activity. Proc Natl Acad Sci USA 1990; 87: 6728-32.

2 Horwell DC, Hughes J, Hunter JC, Pritchard MC, Richardson RS, Roberts E, Woodruff GN. Rationally designed 'dipeptoid' analogues of CCK. $\alpha$-methyltryptophan derivatives as highly selective and orally active gastrin and CCK-B antagonists with potent anxiolytic properties. $\mathcal{H}$ Med Chem 1991; 34: 404-14.

3 Wiesenfeld-Hallin Z, Xu XJ, Hughes J, Horwell DC, Hokfelt T.PD13430, a selective antagonist of cholecystokinin type B receptor enhances the analgesic effect of morphine and receptor enhances the analgesic effect of morphine and synergistically interacts with intrathecal galanin to depress
spinal nociceptive reflexes. Proc Natl Acad Sci USA 1990; 87: 7105-9.
4 Singh L, Lewis AS, Field MJ, Hughes J, Woodruff GN. Evidence for an involvement of the brain cholecystokinin B receptor in anxiety. Proc Natl Acad Sci USA 1991; 88: receptor 1130 - 33 .

5 Hayward NJ, Harding $M$, Lloyd SAC, McKnight AT, Hughes J, Woodruff GN. The effect of CCK-B/gastrin antagonists on stimulated gastric acid secretion in the antagonists on stimulated gastric acid secretion

6 Lotti VJ, Chang RSL. A new potent and selective non-peptide gastrin antagonist and brain cholecystokinin receptor (CCKgastrin antagonist and brain cholecystokinin receptor (CCK-

7 Huang SC, Zhang L, Chiang HCV, Wank SA, Maton PN, Gardner JD, Jensen RT. Benzodiazepine analogues $\mathrm{L} 365,260$ and $\mathrm{L} 364,718$ as gastrin and pancreatic CCK receptor antagonists. Am F Physiol 1989; 257: G169-74.

8 Roche S, Bali JP, Galleyrand JC, Magous R. Characterization of a gastrin-type receptor on rabbit gastric parietal cells using Kolakowski Jr LF, Beinborn M. Expression cloning and characterization of the canine parietal cell gastrin receptor. Proc Natl Acad Sci USA 1992; 89: 3605-9.

10 Reubi JC, Waser B, Horisberger U, Halter F, Soroka CJ, Kumar RR, et al. Identification of somatostatin and gastrin receptors on enterochromaffin-like cells from mastomys gastric tumors. Endocrinology 1992; 131: 166-72.

11 Watson S, Durrant L, Elston P, Morris D. Inhibitory effects of the gastrin receptor antagonist $(L-365,260)$ on gastrointestinal tumor cells. Cancer 1991; 68: 1255-60.

12 Eissele R, Patberg H, Koop H, Krack W, Lorenz W, McKnight AT, Arnold R. Effect of gastrin receptor blockade on endocrine cells in rats during achlorhydria. Gastroenterology 1992; 103: 1596-601.

13 Freidinger RM. Cholecystokinin and gastrin antagonists. Med Res Rev 1989; 9: 271-90.

14 Halter F, Ganguli PC, Marshall M, Crean GP. Preliminary communication of the effect of gastrin II on acid secretion in rats with chronic gastric fistulas. Gastroenterologia 1966; 106: rats with

15 Witzel L, Heitz PU, Halter F, Olah AJ, Varga L, Werner O, Häcki WH. Effects of prolonged administration of metiamide on serum gastrin, gastrin content of the antrum and gastric corpus and G-cell population in the rat. Gastroenterology 1979; 76: 945-9.

16 Chen I-W, Dorley JM, Ramit HG, Pitzenberger SM, Lin JH. Physiological disposition and metabolism of L-365,260, a potent antagonist of brain cholecystokinin receptor, in laboratory animals. Drug Metab Dispos Biol Fate Chem 1992; 20: $390-5$.

17 Koop I, Eissele R, Patberg, Rosskopf B, Koop H, Arnold H. Effect of a new cholecystokinin-(CCK)B-receptor antagonist on the rat pancreas. Proceedings of Conference on Gastrin. on the rat pancreas. Proceedings of Conference on
Dana Point Resort, USA 1992, February 9-12, E-7. 